\begin{tabular}{|c|c|}
\hline $\begin{array}{l}\text { Chemistry of } \\
\text { Metals and Alloys }\end{array}$ & $\begin{array}{l}\text { Chem. Met. Alloys } 9 \text { (2016) 54-60 } \\
\text { Ivan Franko National University of Lviv } \\
\text { www.chemetal-journal.org }\end{array}$ \\
\hline
\end{tabular}

\title{
Crystal structure of the new ternary indide $\operatorname{Pr}_{11} \mathrm{Ge}_{5.21} \mathbf{I n}_{4.79}$
}

\author{
Oksana KRAVETS ${ }^{1}$, Galyna NYCHYPORUK ${ }^{1}$, Ihor MUTS ${ }^{1}$, Zenoviya SHPYRKA ${ }^{1}$, Viktor HLUKHYY ${ }^{2}$, \\ Vasyl' ZAREMBA $^{1 *}$ \\ ${ }^{1}$ Department of Inorganic Chemistry, Ivan Franko National University of Lviv, \\ Kyryla i Mefodiya St. 6, 79005 Lviv, Ukraine \\ ${ }^{2}$ Department of Chemistry, Technische Universität München, Lichtenbergstr. 4, D-85747 Garching, Germany \\ *Corresponding author.Tel.: +380-32-2394483; e-mail:vazar@lnu.edu.ua
}

Received June 1, 2016; accepted June 29, 2016; available on-line November 7, 2016

The new ternary indide $\operatorname{Pr}_{11} \mathrm{Ge}_{5.21} \mathrm{In}_{4.79}$ was synthesized from the elements by arc-melting and subsequent annealing at $870 \mathrm{~K}$. Single crystals were grown by a special annealing procedure in a sealed tantalum container in a resistance furnace. The crystal structure of the compound was determined by $\mathrm{X}$-ray diffraction on a single crystal: $\mathrm{Sm}_{11} \mathrm{Ge}_{4} \mathrm{In}_{6}$ structure type, $I 4 / \mathrm{mmm}, t 184, a=1185.6(2) \mathrm{pm}, c=1654.8(3) \mathrm{pm}$, $w R 2=0.0623,1051 F^{2}$ values, 41 variables. Crystal chemistry in $\operatorname{Pr}_{11} G_{5.21} I_{4.79}$ is discussed from a geometrical point of view.

Crystal structure / Single crystals / Indium

\section{Introduction}

A systematic investigation of ternary $R E-\mathrm{Ge}-\mathrm{In}$ $(R E=$ rare-earth element $)$ systems was recently started, with the aim to determine the character of the interaction of the components in these systems, search for new ternary compounds and study their physical properties. The interaction between the components and isothermal sections of the ternary phase diagrams at $870 \mathrm{~K}$ have been investigated for the systems with $R=\mathrm{Y}$ [1], La [2], Ce [3], Nd [4], Sm [5], Gd [6], Yb [7], and $\mathrm{Lu}$ [8]. Other $R E-\mathrm{Ge}-\mathrm{In}$ systems have only been investigated with the aim to find compounds that belong to particular structure types of intermetallic compounds.

In the ternary systems with rare-earth metals of the cerium subgroup, a larger number of compounds are formed than in the systems with heavy rare-earth metals. The ternary compounds in the $R E-\mathrm{Ge}-\mathrm{In}$ systems crystallize in 8 different structure types, the distribution of which is given in Table 1 .

For some of the $R E$ germanide-indides physical properties have been investigated. The $R E_{2} \mathrm{Ge}_{2} \mathrm{In}$ $(R E=\mathrm{Ce}, \mathrm{Pr}$, and $\mathrm{Nd})$ compounds exhibit localized magnetism of the $R E^{3+}$ ions with complex magnetic behavior hinting to canted antiferromagnetism or spinglass freezing at low temperatures [9]. The $R E_{2} \mathrm{Ge}_{2} \mathrm{In}$ $(R E=\mathrm{Sm}, \mathrm{Gd}, \mathrm{Tb}$, and $\mathrm{Ho})$ compounds are antiferromagnets with Néel temperatures of 25, 42, 51, and $23 \mathrm{~K}$, respectively, whereas $\mathrm{Yb}_{2} \mathrm{Ge}_{2} \mathrm{In}$ is a Pauli paramagnet [10]. Concerning the representatives of the $\mathrm{Sm}_{11} \mathrm{Ge}_{4} \mathrm{In}_{6}$ structure type, $\mathrm{Ce}_{11} \mathrm{Ge}_{4} \mathrm{In}_{6}$ orders ferromagnetically at $T_{\mathrm{C}}=7.5 \mathrm{~K}$ [11], $\mathrm{Gd}_{11} \mathrm{Ge}_{4} \mathrm{In}_{6}$ and $\mathrm{Tb}_{11} \mathrm{Ge}_{4} \mathrm{In}_{6}$ order antiferromagnetically at low temperatures, and $\mathrm{Y}_{11} \mathrm{Ge}_{4} \mathrm{In}_{6}$ is a Pauli paramagnet [12]. The $R E_{11} \mathrm{Ge}_{8} \mathrm{In}_{2}$ compounds ( $\left.R E=\mathrm{Gd}-\mathrm{Tm}\right)$ order ferromagnetically at low temperatures and for the phases with $R E=\mathrm{Gd}$, $\mathrm{Tb}$ and $\mathrm{Tm}$ a magnetocaloric effect was observed with the largest magnetic entropy change $\left(\Delta S_{\mathrm{m}}=10.6 \mathrm{~J} / \mathrm{kg} \mathrm{K}\right)$ for $\mathrm{Tm}_{11} \mathrm{Ge}_{8} \mathrm{In}_{2}$ [13].

During the investigation of the interaction of the components in the Pr-Ge-In system at $870 \mathrm{~K}$, a new indide of composition $\mathrm{Pr}_{11} \mathrm{Ge}_{5.21} \mathrm{In}_{4.79}$ was obtained [14]. The synthesis, structure refinement and crystalchemical peculiarities of this compound are reported here.

\section{Experimental}

Starting materials for the synthesis of the title compound were ingots of praseodymium (Johnson Matthey), germanium pieces (Alfa Aesar), and indium tear drops (Chempur), all with stated purities better than $99.9 \%$. Before the preparation of the alloys, the praseodymium ingots were cut into smaller pieces and arc-melted to small buttons (about 0.5-0.7 g) under an argon atmosphere. Titanium sponge was used as 
Table 1 Structure types of known compounds in the $R E-\mathrm{Ge}-\mathrm{In}$ systems.

\begin{tabular}{|c|c|c|c|c|c|c|c|c|c|c|c|c|c|c|c|}
\hline $\begin{array}{l}\text { Structure } \\
\text { type }\end{array}$ & $\mathrm{Y}$ & $\mathrm{La}$ & $\mathrm{Ce}$ & $\operatorname{Pr}$ & $\mathrm{Nd}$ & $\mathrm{Sm}$ & $\mathrm{Eu}$ & $\mathrm{Gd}$ & $\mathrm{Tb}$ & Dy & Ho & $\mathrm{Er}$ & $\mathrm{Tm}$ & $\mathrm{Yb}$ & $\mathrm{Lu}$ \\
\hline $\mathrm{La}_{3} \mathrm{GeIn}$ & - & + & + & + & + & - & - & + & - & - & - & - & - & - & - \\
\hline $\mathrm{Sm}_{11} \mathrm{Ge}_{4} \mathrm{In}_{6}{ }^{\mathrm{a}}$ & + & + & + & - & + & + & - & + & + & - & + & + & - & - & - \\
\hline $\mathrm{Gd}_{11} \mathrm{Ge}_{8} \mathrm{In}_{2}{ }^{\mathrm{a}}$ & - & - & - & - & - & - & - & + & + & + & + & + & + & - & - \\
\hline $\mathrm{Gd}_{5} \mathrm{Si}_{4}$ & - & + & - & - & - & - & - & - & - & - & - & - & - & - & - \\
\hline $\mathrm{CrB}$ & - & - & - & - & - & - & - & - & - & - & - & - & - & - & + \\
\hline $\mathrm{Mo}_{2} \mathrm{FeB}_{2}$ & + & + & + & + & + & + & - & + & + & + & + & - & - & + & - \\
\hline $\mathrm{La}_{3} \mathrm{GeIn}_{4}$ & - & + & + & + & + & - & - & - & - & - & - & - & - & - & - \\
\hline EuGeIn & - & - & - & - & - & - & + & - & - & - & - & - & - & - & - \\
\hline
\end{tabular}

${ }^{\mathrm{a}}$ The $\mathrm{Sm}_{11} \mathrm{Ge}_{4} \mathrm{In}_{6}$ and $\mathrm{Gd}_{11} \mathrm{Ge}_{8} \mathrm{In}_{2}$ types are ordered versions of the $\mathrm{Ho}_{11} \mathrm{Ge}_{10}$ structure type with different occupation of the $16 m$ position.

getter material. Subsequently, the melted praseodymium buttons were mixed with pieces of germanium and indium tear drops in an atomic ratio of Pr:Ge:In = 2.17:1:1 and arc-melted under the same conditions. The product was re-melted twice to ensure homogeneity. The total weight loss after the melting procedure was less than $0.5 \%$. Then the button was sealed in an evacuated quartz tube and annealed at $870 \mathrm{~K}$ for $720 \mathrm{~h}$. After the arc-melting and the annealing procedures the sample was obtained only in polycrystalline form.

To obtain single crystals suitable for structural investigations, a special thermal treatment was used. The alloy of composition $\operatorname{Pr}_{0.52} \mathrm{Ge}_{0.24} \mathrm{In}_{0.24}$ was powdered and cold-pressed into a pellet. The pellet was put into a small tantalum container, which was sealed in an evacuated silica tube as an oxidation protection. The sample was first heated in a muffle furnace to $1273 \mathrm{~K}$ within $5 \mathrm{~h}$ and held at that temperature for $2 \mathrm{~h}$. Subsequently, the temperature was lowered at a rate of $3 \mathrm{~K} / \mathrm{h}$ to $1073 \mathrm{~K}$, then at a rate of $5 \mathrm{~K} / \mathrm{h}$ to $873 \mathrm{~K}$, held at that temperature for another $12 \mathrm{~h}$, and finally cooled to room temperature by switching off the furnace. The temperature was controlled by a $\mathrm{CrNi}-\mathrm{Ni}$ thermocouple with a "Eurotherm 118" thermoregulator. As a result, irregularly shaped single crystals were obtained.

Single crystals were selected by mechanical fragmentation from the sample submitted to the special thermal treatment. They were examined by Laue method on a RKV-86 camera (white molybdenum radiation, photo technique) in order to check the quality and to determine the symmetry. Intensity data of $\operatorname{Pr}_{11} \mathrm{Ge}_{5.21} \mathrm{In}_{4.79}$ were collected at room temperature using an Oxford Diffraction Xcalibur 3 diffractometer with graphite-monochromatized Mo $K_{\alpha}$ $(\lambda=71.073 \mathrm{pm})$ radiation. The raw data were corrected for background, polarization, and Lorentz factor. A numerical absorption correction was applied $[15,16]$. The crystallographic parameters and relevant data for the data collection and evaluations are listed in Table 2.

The single crystals investigated on the diffractometer were analyzed using a JEOL SEM 5900 LV scanning electron microscope with $\mathrm{PrF}_{3}$, Ge, and InAs as standards. No impurity elements heavier than sodium were observed. For the $\operatorname{Pr}_{11} \mathrm{Ge}_{5.21} \mathrm{In}_{4.79}$ crystal the composition determined by EDX $(51 \pm 2$ at. $\% \mathrm{Pr}$ : $26 \pm 2$ at. $\%$ Ge : $23 \pm 2$ at.\% In) is in good agreement with the refined composition (52.4:24.8:22.8).

\section{Results and discussion}

\subsection{Structure refinements}

The isotypism of the investigated compound with $\mathrm{Sm}_{11} \mathrm{Ge}_{4} \mathrm{In}_{6}$ [5] was already evident from the powder patterns (powder diffractometer Stoe Stadi P, Cu $K_{\alpha}$ radiation). The analysis of the Laue photos from selected single crystals confirmed tetragonal symmetry. The X-ray diffraction data set revealed an I-centered tetragonal lattice and the systematic extinctions were in agreement with the space group I4/mmm. The atomic parameters of $\mathrm{Ce}_{11} \mathrm{Ge}_{4.74} \mathrm{In}_{5.26}$ [11] were taken as starting values and the structure was refined using SHELXL-97 (full-matrix leastsquares on $F^{2}$ ) [17,18] with anisotropic atomic displacement parameters for all atoms. As a check for the correct composition and site assignment, the occupancy parameters were refined in separate series of least-squares cycles along with the displacement parameters. The site in Wyckoff position $16 \mathrm{~m}$ showed mixed occupancy of indium and germanium atoms (Table 3), as observed for the structure of $\mathrm{Ce}_{11} \mathrm{Ge}_{4.74} \mathrm{In}_{5.26}$ [11]. The occupancy parameters were refined as a least-square variable in the final cycles, giving the final composition $\operatorname{Pr}_{11} \mathrm{Ge}_{5.21(1)} \mathrm{In}_{4.79(1)}$. All the other sites were fully occupied within two standard uncertainties. The final difference Fourier synthesis was flat and revealed no significant residual peaks 
Table 2 Crystal data and structure refinement for $\operatorname{Pr}_{11} \mathrm{Ge}_{5.21} \mathrm{In}_{4.79}$ (space group $I 4 / \mathrm{mmm}, Z=4$ ).

\begin{tabular}{|c|c|}
\hline Empirical formula & $\operatorname{Pr}_{11} \mathrm{Ge}_{5.21} \mathrm{In}_{4.79}$ \\
\hline Formula weight, $\mathrm{g} \mathrm{mol}^{-1}$ & 2325.9 \\
\hline Unit cell dimensions $\mathrm{nm}$ & $a=1185.6(2)$ \\
\hline Unit cell dimensions, pm & $c=1654.8(3)$ \\
\hline Unit cell volume, $\mathrm{nm}^{3}$ & 0.2326 \\
\hline Pearson code & $t I 84$ \\
\hline Wyckoff sequence & $n^{2} m j h^{2} e^{2} d$ \\
\hline Calculated density, $\mathrm{g} \mathrm{cm}^{-3}$ & 7.077 \\
\hline Crystal size, $\mu \mathrm{m}^{3}$ & $20 \times 30 \times 120$ \\
\hline Absorption coefficient $\mu\left(\right.$ Mo $\left.K_{\alpha}\right), \mathrm{mm}^{-1}$ & 33.76 \\
\hline$F(000), \mathrm{e}$ & 4202 \\
\hline$\theta$ range for data collection, ${ }^{\circ}$ & $4.04-30.54$ \\
\hline Range in $h k l$ & $\pm 16, \pm 16, \pm 23 / 21$ \\
\hline Total no. reflections & 23622 \\
\hline Independent reflections / $R_{\text {int }}$ & $1051 / 0.0158$ \\
\hline Reflections with $I>2 \sigma(I) / R_{\sigma}$ & $1018 / 0.0653$ \\
\hline Data / parameters & $1051 / 41$ \\
\hline Goodness-of-fit on $F^{2}$ & 1.07 \\
\hline$R 1 / w R 2$ for $I>2 \sigma(I)$ & $0.0308 / 0.0623$ \\
\hline$R 1 / w R 2$ (all data) & $0.0329 / 0.0632$ \\
\hline Extinction coefficient & $0.00010(1)$ \\
\hline Largest diff. peak / hole, e $\AA^{-3}$ & $1.65 /-1.28$ \\
\hline
\end{tabular}

Table 3 Atomic coordinates and anisotropic displacement parameters $\left(\mathrm{pm}^{2}\right)$ for $\operatorname{Pr}_{11} \mathrm{Ge}_{5.21} \mathrm{In}_{4.79}$.

\begin{tabular}{c|c|c|c|c|c}
\hline Atom & $\begin{array}{c}\text { Wyckoff } \\
\text { position }\end{array}$ & $x$ & $Y$ & $z$ & $U_{\text {eq. }}, \mathrm{pm}^{2}$ \\
\hline $\mathrm{Pr}^{1}$ & $16 n$ & 0 & $0.2518(1)$ & $0.3105(1)$ & $195(1)$ \\
$\mathrm{Pr}^{2}$ & $16 n$ & 0 & $0.3432(1)$ & $0.0976(1)$ & $187(1)$ \\
$\mathrm{Pr}^{3}$ & $8 h$ & $0.3317(1)$ & $0.3317(1)$ & 0 & $188(2)$ \\
$\mathrm{Pr}^{4}$ & $4 e$ & 0 & 0 & $0.1629(1)$ & $192(2)$ \\
$\mathrm{Ge}^{1}$ & $8 j$ & $0.1546(1)$ & $1 / 2$ & 0 & $181(3)$ \\
$\mathrm{Ge}^{2}$ & $4 d$ & 0 & 0 & $0.3789(1)$ & $187(4)$ \\
$\mathrm{Ge}^{3}$ & $4 e$ & 0 & $1 / 2$ & $1 / 4$ & $174(4)$ \\
$\mathrm{In}^{1}$ & $8 h$ & $0.1280(1)$ & $0.1280(1)$ & 0 & $178(2)$ \\
$M^{\mathrm{a}}$ & $16 m$ & $0.2074(1)$ & $0.2074(1)$ & $0.1705(1)$ & $206(3)$ \\
\hline
\end{tabular}

\begin{tabular}{c|c|c|c|c|c|c}
\hline Atom & $U_{11}$ & $U_{22}$ & $U_{33}$ & $U_{23}$ & $U_{13}$ & $U_{12}$ \\
\hline $\operatorname{Pr}^{1}$ & $228(3)$ & $174(3)$ & $183(3)$ & $-4(2)$ & 0 & 0 \\
$\operatorname{Pr}^{2}$ & $183(3)$ & $170(3)$ & $208(3)$ & $4(2)$ & 0 & 0 \\
$\operatorname{Pr}^{3}$ & $180(2)$ & $180(2)$ & $205(3)$ & 0 & 0 & $34(3)$ \\
$\operatorname{Pr}^{4}$ & $184(3)$ & $184(3)$ & $206(5)$ & 0 & 0 & 0 \\
$\mathrm{Ge}^{1}$ & $151(7)$ & $169(7)$ & $223(7)$ & 0 & 0 & 0 \\
$\mathrm{Ge}^{2}$ & $167(6)$ & $167(6)$ & $228(10)$ & 0 & 0 & 0 \\
$\mathrm{Ge}^{3}$ & $172(6)$ & $172(6)$ & $178(9)$ & 0 & 0 & 0 \\
$\mathrm{In}^{1}$ & $168(3)$ & $168(3)$ & $199(4)$ & 0 & 0 & $11(3)$ \\
$M^{\mathrm{a}}$ & $199(3)$ & $199(3)$ & $219(4)$ & $-1(2)$ & $-1(2)$ & $27(3)$ \\
\hline
\end{tabular}

${ }^{\mathrm{a}} M=0.696(13) \mathrm{In}+0.304(13) \mathrm{Ge}$

(Table 2). The positional parameters and interatomic distances of the refinements are listed in Tables 3 and 4 , respectively.

Further details of the structure refinements may be obtained from the Fachinformationszentrum Karlsruhe, D-76344 Eggenstein-Leopoldshafen (Germany), by quoting the Registry No. CSD-427929 $\left(\operatorname{Pr}_{11} \mathrm{Ge}_{5.21} \operatorname{In}_{4.79}\right)$.

\subsection{Crystal chemistry and bonding}

The investigated compound is a representative of the $\mathrm{Sm}_{11} \mathrm{Ge}_{4} \mathrm{In}_{6}$-type [5], which is an ordered variant of the $\mathrm{Ho}_{11} \mathrm{Ge}_{10}$-type [19]. The structure contains nine crystallographically independent sites with Wyckoff sequence $n^{2} m j h^{2} e^{2} d$. A projection of the structure of $\operatorname{Pr}_{11} \mathrm{Ge}_{5.21} \mathrm{In}_{4.79}$ onto the $X Z$ plane and the coordination polyhedra of the atoms are presented in Fig. 1. 
Table 4 Interatomic distances $(\delta, \mathrm{pm})$ in $\operatorname{Pr}_{11} \mathrm{Ge}_{5.21} \mathrm{In}_{4.79}$ (standard deviations equal or less than $0.2 \mathrm{pm}$ ).

\begin{tabular}{l|l|l}
\hline \multicolumn{2}{c|}{ Atom } & $\delta, \mathrm{pm}$ \\
\hline \multirow{5}{*}{$\operatorname{Pr}^{1}$} & $\mathrm{Ge}^{3}$ & 310.8 \\
& $\mathrm{Ge}^{2}$ & 319.3 \\
& $\mathrm{Ge}^{1}$ & 332.6 \\
& $2 \mathrm{M}$ & 341.9 \\
& $\operatorname{Pr}^{2}$ & 368.6 \\
& $2 \operatorname{Pr}^{2}$ & 379.8 \\
& $2 \operatorname{Pr}^{3}$ & 384.6 \\
& $\operatorname{Pr}^{4}$ & 385.8 \\
\hline \multirow{5}{*}{$\operatorname{Pr}^{2}$} & $2 \mathrm{Ge}^{1}$ & 307.0 \\
& $\mathrm{Ge}^{3}$ & 313.3 \\
& $2 \mathrm{M}$ & 317.7 \\
& $\operatorname{Pr}^{2}$ & 323.0 \\
& $2 \mathrm{In}^{1}$ & 338.0 \\
& $\operatorname{Pr}^{1}$ & 368.6 \\
& $\operatorname{Pr}^{2}$ & 371.8 \\
& $2 \operatorname{Pr}^{1}$ & 379.8 \\
\hline \multirow{5}{*}{$\operatorname{Pr}^{3}$} & $2 \mathrm{Ge}^{1}$ & 289.6 \\
& $\mathrm{In}^{1}$ & 341.6 \\
& $2 \mathrm{Ge}^{2}$ & 346.1 \\
& $2 \mathrm{M}$ & 350.7 \\
& $4 \operatorname{Pr}^{1}$ & 384.6 \\
& $2 \operatorname{Pr}^{3}$ & 399.1 \\
\hline \multirow{5}{*}{} & &
\end{tabular}

\begin{tabular}{l|l|l}
\hline \multicolumn{2}{|c|}{ Atom } & $\delta, \mathrm{pm}$ \\
\hline \multirow{4}{*}{$\operatorname{Pr}^{4}$} & $4 \mathrm{In}$ & 344.5 \\
& $4 \mathrm{M}$ & 348.0 \\
& $\mathrm{Ge}^{2}$ & 357.5 \\
& $4 \operatorname{Pr}^{1}$ & 385.8 \\
\hline \multirow{5}{*}{$\mathrm{In}$} & $2 \mathrm{In}$ & 303.4 \\
& $2 \mathrm{M}$ & 312.0 \\
& $4 \operatorname{Pr}^{2}$ & 338.0 \\
& $\operatorname{Pr}^{3}$ & 341.6 \\
& $2 \operatorname{Pr}^{4}$ & 344.5 \\
\hline \multirow{5}{*}{$\mathrm{Ge}^{1}$} & $2 \operatorname{Pr}^{3}$ & 289.6 \\
& $4 \operatorname{Pr}^{2}$ & 307.0 \\
& $2 \operatorname{Pr}^{1}$ & 332.6 \\
& $\mathrm{Ge}^{1}$ & 366.6 \\
\hline \multirow{3}{*}{$\mathrm{Ge}^{2}$} & $4 \operatorname{Pr}^{1}$ & 319.3 \\
& $4 \operatorname{Pr}^{3}$ & 346.1 \\
\hline \multirow{2}{*}{$\mathrm{Ge}^{3}$} & $\operatorname{Pr}^{4}$ & 357.5 \\
\hline \multirow{5}{*}{$M$} & $4 \operatorname{Pr}^{1}$ & 310.8 \\
& $4 \operatorname{Pr}^{2}$ & 313.3 \\
\hline & $2 \operatorname{Pr}^{2}$ & 317.7 \\
& $2 \operatorname{Pr}^{1}$ & 341.9 \\
& $\operatorname{Pr}^{4}$ & 348.0 \\
& $\operatorname{Pr}^{3}$ & 350.7 \\
& $2 \operatorname{Pr}^{1}$ & 351.6 \\
\hline
\end{tabular}

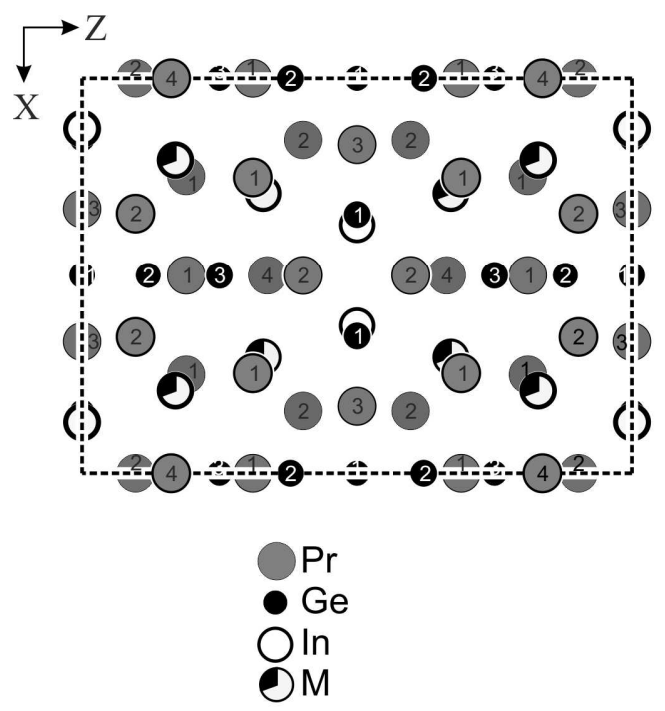

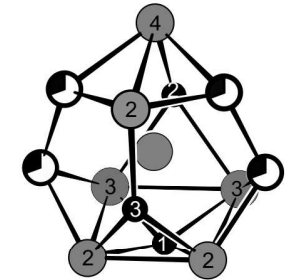

$\operatorname{Pr} 1$ (.m.)

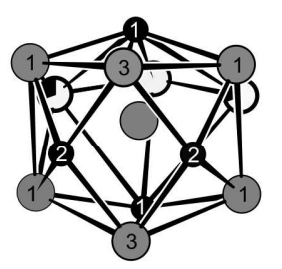

$\operatorname{Pr} 3(m .2 m)$

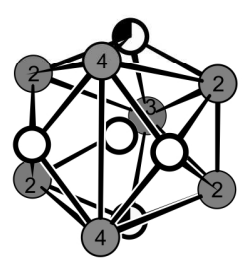

In $(m .2 m)$

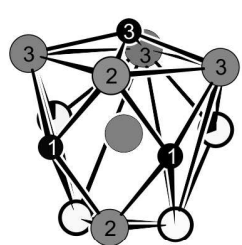

Pr2 (.m.)

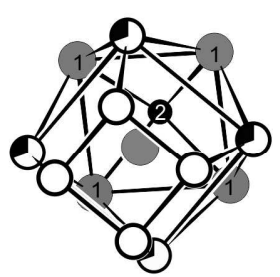

Pr4 $(4 \mathrm{~mm})$

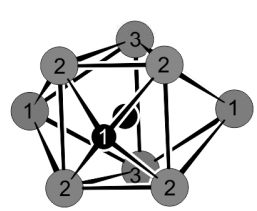

Ge1 (m2m.)

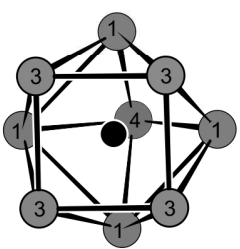

$\mathrm{Ge} 2(4 \mathrm{~mm})$

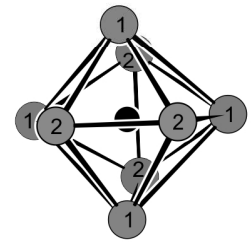

Ge3 ( $\overline{4} m 2)$

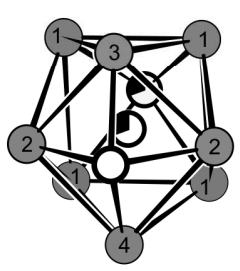

$M(. . m)$

Fig. 1 Projection of the structure of $\operatorname{Pr}_{11} \mathrm{Ge}_{5.21} \mathrm{In}_{4.79}$ onto the $X Z$ plane and coordination polyhedra of the atoms. The site symmetries are indicated. 
The coordination environments of the praseodymium atoms can be described by two different types of polyhedron. The coordination polyhedra of the $\operatorname{Pr} 1 / \operatorname{Pr} 3$ atoms (coordination number $\mathrm{CN}=13)$ and $\operatorname{Pr} 2$ atoms $(\mathrm{CN}=12)$ are distorted pentagonal antiprisms with three and two additional atoms, respectively. The polyhedra of the Pr4 atoms $(\mathrm{CN}=13)$ can be considered as intermediate between tetragonal prisms and tetragonal anti-prisms with a capped base. For the atoms of the statistical mixture $M=\mathrm{In} / \mathrm{Ge}$, the coordination polyhedra are tetragonal antiprisms with two additional atoms above the bases $(\mathrm{CN}=10)$. The coordination polyhedra of the indium atoms are tetragonal antiprisms with two indium atoms situated above edges and one praseodymium atom above the base $(\mathrm{CN}=11)$. The atoms of the smallest element $(\mathrm{Ge})$ are surrounded by three types of polyhedron: a trigonal prism with three additional atoms above the side faces for the $\mathrm{Ge} 1$ atoms
$(\mathrm{CN}=9)$, a tetragonal antiprism with one capped basis for the $\mathrm{Ge} 2$ atoms $(\mathrm{CN}=9)$ and a distorted tetragonal prism for the $\mathrm{Ge} 3$ atoms $(\mathrm{CN}=8)$.

The interatomic distances In-In (303.4 pm), In- $M$ $(312.0 \mathrm{pm})$, and $M-M(299.3 \mathrm{pm})$ are all shorter than the In-In distances in the structure of elemental indium $(325-338 \mathrm{pm})$ [20]. Similar values of the corresponding interatomic distances were observed for $\mathrm{Ce}_{11} \mathrm{Ge}_{4.74} \mathrm{In}_{5.26}$ [11] and the recently discovered $\mathrm{Ce}_{11} \mathrm{Ge}_{5.96} \mathrm{In}_{4.04}$ [21]. No short Ge-Ge contacts were observed in any of these compounds.

A characteristic feature of the ternary compounds in the $R E-\mathrm{Ge}-\mathrm{In}$ systems is the formation of polyanionic $p$-block element (In, Ge or $\mathrm{Ge} / \mathrm{In}$ ) substructures. On the basis of the analysis of the interatomic distances, the $p-p$ interactions are dominant in the compounds with $\mathrm{Sm}_{11} \mathrm{Ge}_{4} \mathrm{In}_{6}$-type structures (In-In and In/Ge-In/Ge bonding, Fig. 2a), $\mathrm{La}_{3} \mathrm{GeIn}_{4}$-type structures (In-In bonding, Fig. 2b) [11],

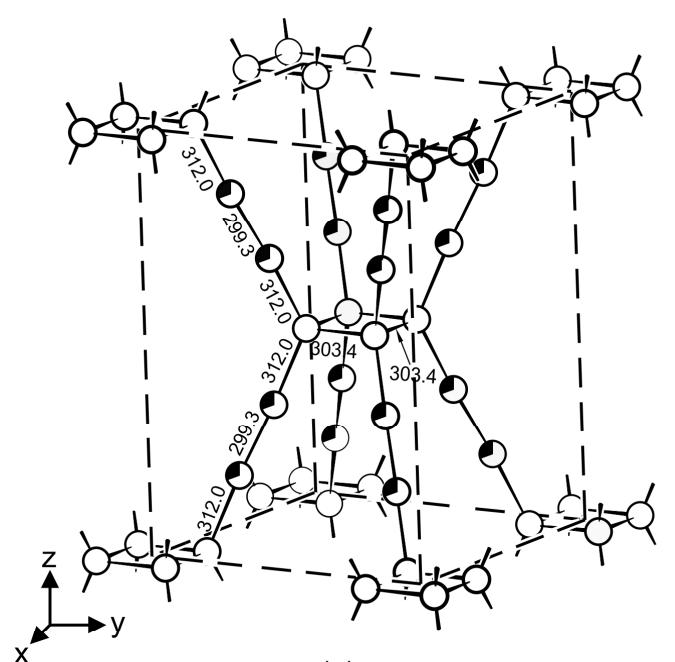

(a)

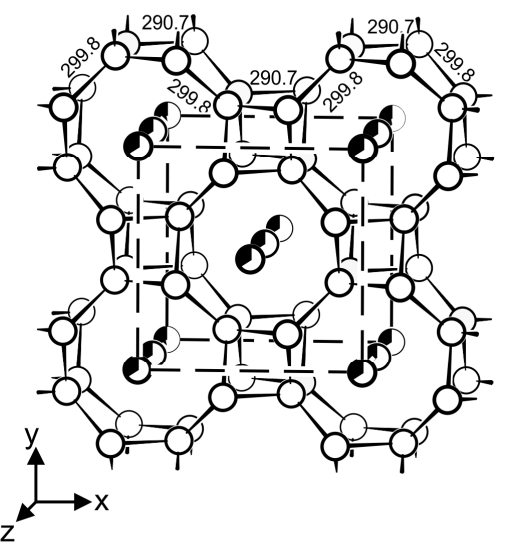

(b)
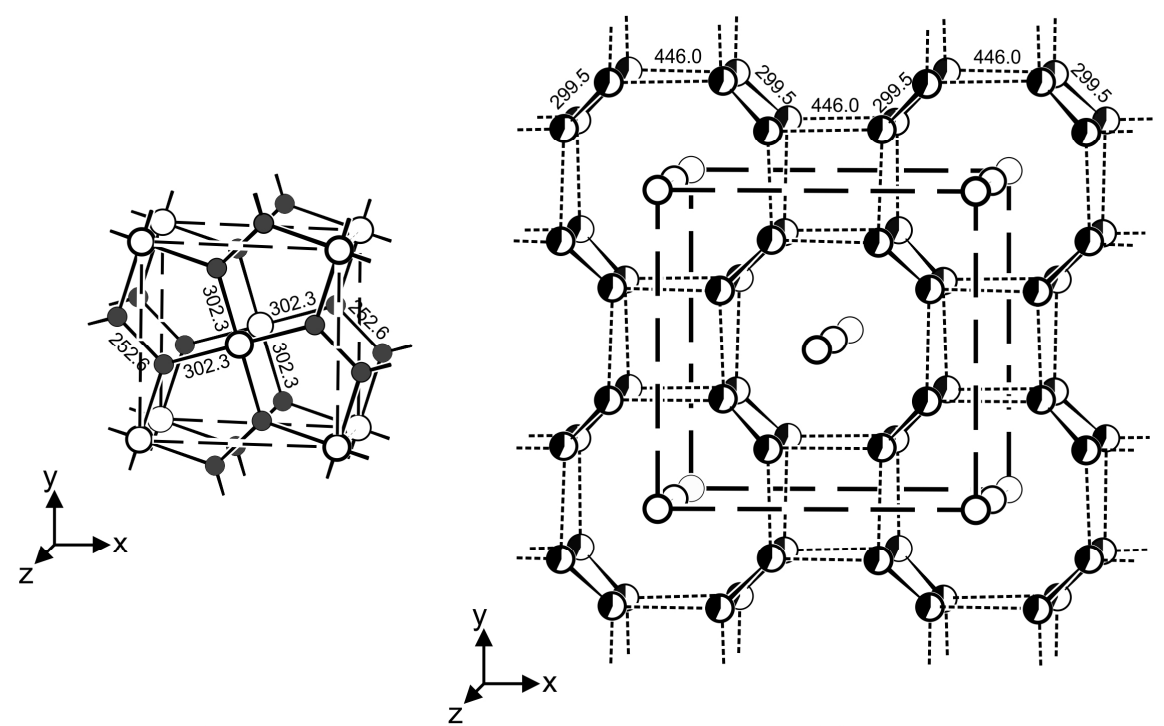

(c)

(d)

Fig. 2 The polyanionic In-Ge substructures in the structures of $\operatorname{Pr}_{11} \mathrm{Ge}_{5.21} \mathrm{In}_{4.79}$ (a), $\mathrm{Ce}_{3} \mathrm{Ge}_{0.66} \mathrm{In}_{4.34}$ (b), $\mathrm{Ce}_{2} \mathrm{Ge}_{2} \mathrm{In}(\mathrm{c})$, and $\mathrm{Nd}_{3} \mathrm{Ge}_{1.18} \mathrm{In}_{0.82}$ (d). Indium and germanium atoms are drawn as open and black filled circles, respectively, and the mixed-occupied sites are emphasized by segments. 
and $\mathrm{Mo}_{2} \mathrm{FeB}_{2^{-}}$type structures (Ge-Ge bonding, Fig. 2c) [22], indicating a significant level of covalency. By contrast, in the structures of the $R E$-rich $\mathrm{La}_{3}$ GeIn-type compounds, the contacts $M-M$ $(M=\mathrm{Ge} / \mathrm{In})$ have only a weak influence on the chemical bonding (Fig. 2d) [23].

In the structure of $\operatorname{Pr}_{11} \mathrm{Ge}_{5.21} \mathrm{In}_{4.79}$ the threedimensional indium/germanium substructure (Fig. 2a) is built up from two different rings, $\mathrm{In}_{4}$ and $(\mathrm{In} / \mathrm{Ge})_{14}$, which are interconnected in the $a b$ plane. At this point one has to keep in mind that only the $M$ site within the
$\mathrm{In}_{14}$ rings shows $\mathrm{In} / \mathrm{Ge}$ mixed occupancy. Along the $c$-axis the In- $M$ network forms channels, which are filled by $1 \mathrm{D}$-chains of condensed polyhedra centered by $\mathrm{Ge}^{1}$ and $\mathrm{Ge}^{3}$ atoms (Figs. 3a-c). Furthermore, these 1D-chains are interconnected via coordination polyhedra of the $\mathrm{Ge}^{2}$ atoms into a complex 3D-framework (Figs. 3d,e). Note that the $\mathrm{In}_{4}$ squares with the shortest In-In contacts (303.4 pm) sharing the $\mathrm{Ge}^{2}$ polyhedra, play an important role in the stabilization of the structure of $\operatorname{Pr}_{11} \mathrm{Ge}_{5.21} \mathrm{In}_{4.79}$.

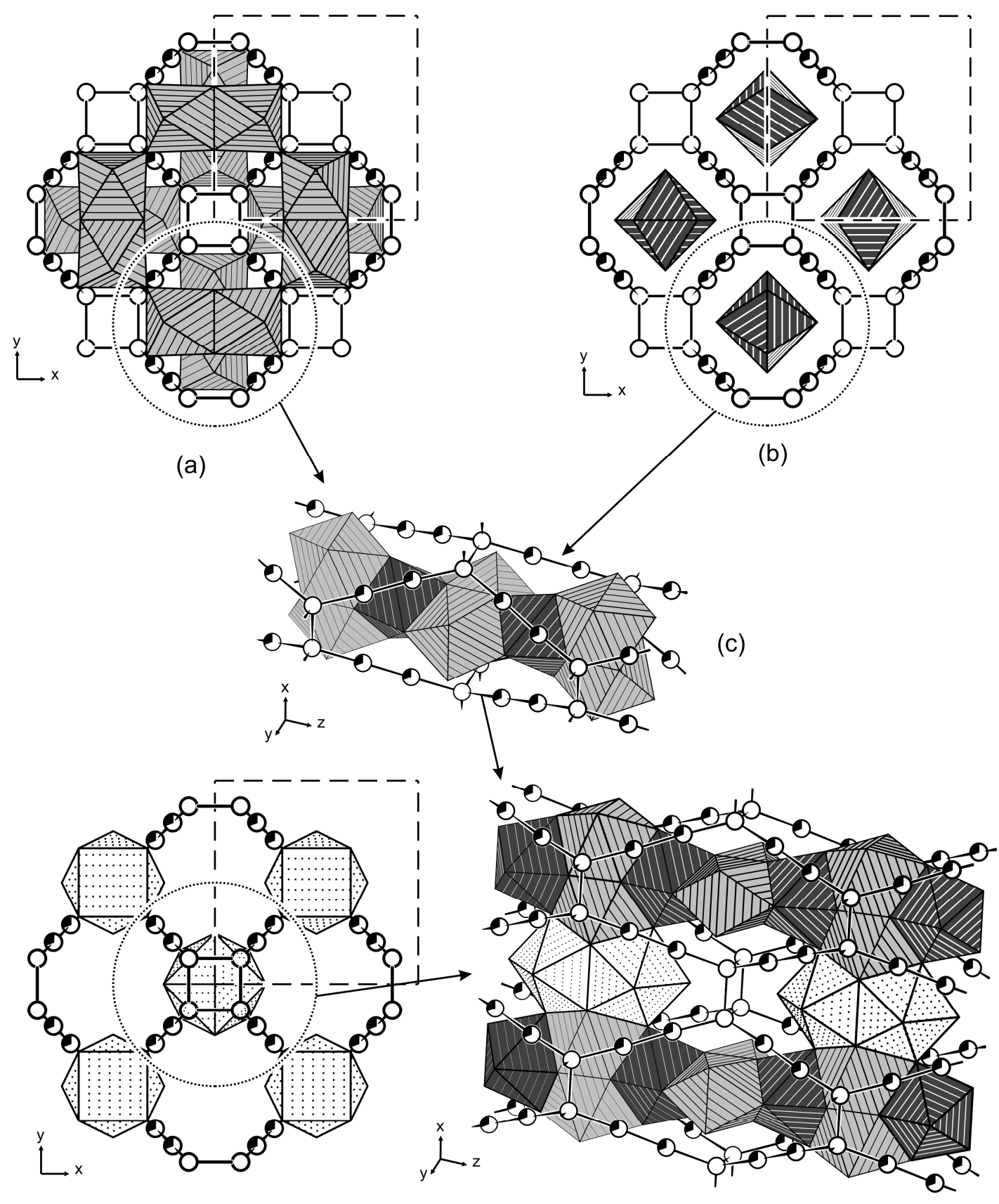

(d)

(e)

Fig. 3 Three-dimensional framework formed by the coordination polyhedra of the germanium atoms in $\operatorname{Pr}_{11} \mathrm{Ge}_{5.21} \mathrm{In}_{4.79}$. This 3D-framework of Ge-centered polyhedra is interpenetrated by the In- $M$ network. 


\section{References}

[1] Yu.B. Tyvanchuk, V.I. Zaremba, Ya.M. Kalychak, Visn. Lviv. Univ., Ser. Khim. 38 (1999) 50.

[2] G.P. Nychyporuk, V.I. Zaremba, Ya.M. Kalychak, Visn. Lviv. Univ., Ser. Khim. 41 (2002) 49.

[3] G. Nychyporuk, V. Zaremba, Ya. Kalychak, Visn. Lviv. Univ., Ser. Khim. 43 (2003) 9.

[4] O. Kravets, G. Nychyporuk, V. Zaremba, Visn. Lviv. Univ., Ser. Khim. 50 (2009) 133.

[5] Yu. Tyvanchuk, K. Miliyanchuk, V. Zaremba, J. Stepien-Damm, Ya. Kalychak, Ukr. Zh. Khim. 67 (2001) 15.

[6] Yu. Tyvanchuk, V. Zaremba, Ya. Kalychak, Visn. Lviv. Univ., Ser. Khim. 48. (2007) 154.

[7] Yu.B. Tyvanchuk, V.I. Zaremba, Ya.M. Kalychak, Visn. Lviv. Univ., Ser. Khim. 41 (2002) 8.

[8] Yu.B. Tyvanchuk, Ya.M. Kalychak, V.I. Zaremba, L.D. Gulay, Pol. J. Chem. 79 (2002) 491.

[9] V.I. Zaremba, D. Kaczorowski, G.P. Nychyporuk, U.Ch. Rodewald, R. Pöttgen, Solid State Sci. 6 (2004) 1301.

[10] P.H. Tobash, D. Lins, S. Bobev, A. Lima, M.F. Hundley, J.D. Thompson, J.L. Sarrao, Chem. Mater. 17 (2005) 5567.

[11] V.I. Zaremba, D. Kaczorowski, G.P. Nychyporuk, U.Ch. Rodewald, B. Heying, R. Pöttgen, Z. Anorg. Allg. Chem. 632 (2006) 975.
[12] Yu. Tyvanchuk, R. Duraj, T. Jaworska-Golab, S. Baran, Ya.M. Kalychak, J. Przewoznik, A. Szytula, Intermetallics 25 (2012) 18.

[13] Y.Y.J. Cheung, V. Svitlyk, Yu. Mozharivskyj, Intermetallics 19 (2011) 276.

[14] O. Kravets, G. Nychyporuk, R. Serkiz, D. Kaczorovski, V. Zaremba, Visn. Lviv. Univ., Ser. Khim. 57 (2016) (in press).

[15] X-RED32, Version 1.48, STOE \& Cie $\mathrm{GmbH}$, Darmstadt, Germany, 2008.

[16] X-SHAPE, Version 2.11, STOE \& Cie GmbH, Darmstadt, Germany, 2008.

[17] G.M. Sheldrick, SHELXL-97 - Programs for the Solution and Refinement of Crystal Structures, University of Göttingen, Germany, 1997.

[18] G.M. Sheldrick, Acta Crystallogr. A 64 (2008) 112.

[19] G.S. Smith, Q. Johnson, A.G. Tharp, Acta Crystallogr. 23 (1967) 640.

[20] J. Donohue, The Structures of the Elements, John Wiley \& Sons, New York, USA, 1974.

[21] B.-Y. Jeon, J. Jeon, J. Lee, J. Kim, T.-S. You, J. Alloys Compd. 620 (2015) 269.

[22] V.I. Zaremba, D. Johrendt, U.Ch. Rodewald, G.P. Nychyporuk, R. Pöttgen, Solid State Sci. 7 (2005) 998.

[23] O. Kravets, G. Nychyporuk, I. Muts, V. Hlukhyy, R. Pöttgen, V. Zaremba, Solid State Sci. 7 (2005) 998. 